\title{
Environmental social controls and capital investments: Australian evidence
}

\author{
Dorothy Wood ${ }^{\mathrm{a}}$, Donald G. Ross ${ }^{\mathrm{b}}$ \\ ${ }^{a}$ School of Accounting and Business Information Systems, Australian National University, \\ Canberra, 0200, Australia \\ ${ }^{\mathrm{b}}$ Macquarie Graduate School of Management, Macquarie University, Sydney, 2109, Australia
}

\begin{abstract}
Environmental social controls (ESCs) such as mandatory disclosure, regulations, subsidies, and stakeholder opinion are intended to improve firm environmental performance. This paper reports ESC importance to Australian financial managers in making capital investment decisions. A decision-making experiment showed managers to be most responsive to stakeholder opinion (42 per cent), followed by subsidization ( 26 per cent) and regulatory cost ( 22 per cent). Mandatory disclosure has very little influence (10 per cent). ESC interaction effects are limited so coordination of ESC policy is not a primary concern. High degrees of managerial self-insight suggest policy changes would be enhanced by close consultations with the managers involved.
\end{abstract}

Key words: Capital budgeting; Environmental social controls

JEL classification: G31, Q56

doi: $10.1111 / \mathrm{j} .1467-629 x .2006 .00180 . \mathrm{x}$

\section{Introduction}

The cost of pollution and other environmental damage has been largely borne by society. Now social expectations and 'user pays' environmental regulations require firms to internalize some of this cost. Increased voluntarism and market-based measures have lead to calls for evaluation of existing environmental policies (Bennear and Coglianese, 2005). Cohen (1997) questions why some firms reduce pollution more, which regulations are most effective, and whether non-regulatory programmes supplement or replace more stringent regulations. Skidmore (1997) advises governments to develop policy frameworks and precise incentive mechanisms

Received 19 September 2003; accepted 26 July 2005 by Robert Faff (Editor).

(C) The Authors

Journal compilation (C) 2006 AFAANZ 
to encourage innovation. Gunningham et al. (1998) call for work to determine the optimal regulatory mix to induce improvements in environmental performance.

The present paper replies to these calls for research by examining the potential influence of selected Australian environmental social controls (ESCs) on capital investment decision-making. The paper provides the first integrated examination of key Australian ESCs and innovatively uses factorial experimentation to estimate the causal effect of each of the ESC treatments on capital investment acceptability. This use of experimentation substantially expands the Australian extant literature.

The ESCs examined are: (i) mandatory disclosure, meaning environmental disclosure required by law and accounting standards; (ii) regulatory costs, meaning direct payments on pollutant emissions, clean-up costs, and/or regulatory compliance; (iii) subsidization, meaning depreciation allowances that provide higher tax benefits; and (iv) stakeholder opinion, meaning how the investment will be approved by various non-government stakeholder groups such as shareholders, creditors, and customers.

These ESCs are posited to have a socially beneficial effect, imposing costs and benefits that drive the firm towards less polluting investment. They might be viewed as 'carrots' such as subsidies, better reputation and increased market share; or as 'sticks' such as fines and penalties, poor reputation and loss of market share. If ESCs are inefficient there are high implementation and health and welfare costs to the community.

Environmental Protection Authorities (EPA) are especially aware of the importance of capital investment to cleaner production. The EPA (NSW) (1994) discussion of the Hunter Valley Salinity Trading Scheme indicates that one aim of the scheme was to encourage investment in water storage facilities to reduce output of saline water into the Hunter River. The US EPA has funded several major studies of capital investment (White et al., 1995; Boyd, 1998). The importance of capital investment decisions overall is highlighted in the following comment:

Capital investment decisions must rank as one of the most important forms of decisions made in our economic society: in aggregate across different sectors of the economy they account for a large proportion of the natural resources and set the course of activities for the next generation. To the individual enterprise, whether public or private, the success of these decisions will affect its very survival and future prosperity. (Butler et al., 1993, p. 49)

In the present paper, a series of hypothetical cases was used to measure the responsiveness of individual Australian capital investment managers to 'better' and 'worse' ESCs than they currently experience. The paper proceeds with the literature supporting investigation into mandatory disclosure, regulatory costs, subsidization, and stakeholder opinion. The research objectives are then presented in terms of establishing: (i) the relative importance of each individual ESC; (ii) their interactive influence; and (iii) manager self-insight into ESC influence. The experiment and the study population are then detailed. The 
results are presented for ESC relative importance by self-reported weightings, magnitude of effect proportions, and effect size measurements. Additional insights on cue configurality and self-insight are then provided.

\section{Background and prior research}

The boundary between regulation and market forces is increasingly blurred with the introduction of economic instruments that act on market forces. Little is known of the extent to which ESCs are effective (either individually or collectively) in influencing firms to invest in less-polluting plant and equipment. Presented below is a review of the literature beginning with integrated studies that compare or evaluate ESCs. This is followed by an examination of the selected ESCs. Literature setting out the nature of human information processing and capital investment decisions completes the review.

\subsection{Integrated studies}

Until recently, research into ESCs appeared fragmented and lacked integration. However, new studies are emerging, which consider joint ESC influence. Bansal and Gangopadhyay (2003) consider the use of subsidies and taxes to improve environmental policy. Moraga-Gonzalez and Padron-Fumero (2002) examine 'frequently used environmental policies in a duopolistic market where consumers are willing to pay more for less-polluting goods'. They examine the effects of unit emission standards, technology subsidies and product charges on unit emissions, industrial aggregate effluents and social welfare. They predict technology subsidization to be welfare improving. ${ }^{1}$

Managerial economics provides work more closely related to the present study, with empirical studies of environmental social control such as taxes (Verbeke and Coeke, 1997) and regulation (Cohen, 1997; Boyd, 1998). Boyd (1998, p. 54) considers that firms are 'uniquely capable of evaluating' the profitability of environmental investments. Boyd's study provides a rich description of environmental capital investment practices of US firms, although it pays little attention to the use of social controls or the introduction of economic instruments.

Prakash and Kollman (2004, p. 109) consider that 'from a policy perspective, it is important to understand how the regulatees perceive the benefits and costs of various policy types, and why they exhibit varying levels of responses' and note that each of these categories 'constitutes an analytically separate policy approach to deal with environmental challenges' (Prakash and Kollman, 2004, p. 108). Unfortunately, Prakash and Kollman's (2004) study does not extend to an empirical investigation of firm responses to policy instruments.

\footnotetext{
${ }^{1}$ It is interesting to note that although both of these studies found the use of subsidies to be beneficial, subsidies in Australia are little used.

(C) The Authors

Journal compilation (C) 2006 AFAANZ
} 
Gunningham et al. (1998) review the development of environmental regulation and investigate the mix of environmental instruments in Australia. Gunningham et al. (1998) note that policies have 'tended to develop in ad hoc manner' and have rarely been used to full potential (pp. 13-14). They suggest that there has been insufficient systematic enquiry into how the selected instruments might interact with each other and other forms of regulation. Follow-up work by Gunningham et al. (2003) evaluates social and regulatory pressures on corporate environmental performance of pulp and paper mills located in the USA, Canada, Australia and New Zealand. They find a similar range of environmental performance results in all four countries, with no regulatory regime doing uniformly better or worse than others. Management style was considered to be a source of variance as managers at different mills dealt with regulatory and social pressures in different ways. Moreover, ESC interactions are evident in their comment:

(W)e found these external factors, rather than being independent, often gain their force through mutual interaction; that far from being unambiguous, the responses they demand are often unclear; and hence they do not operate unidirectionally, for their thrust and content often are determined by the way regulated enterprises interpret, confront and counter them.

\subsection{Mandatory disclosure}

Australian regulations governing public disclosure of firm environmental performance are very limited (ICAA, 1998; Nash and Awty, 2001). They include National Pollutant Inventory Internet disclosure of pollutants for industrial facilities and accounting standard and Corporations Act disclosures required in corporate annual reports. Annual report disclosure requirements for corporations or their parts (relevant to the selected industries) include Corporations Act requirements for disclosure in the Directors' Report. Additionally, some environmental disclosures are required by Australian accounting and auditing standards.

Evidence from the published literature (Schmidheiny and Zorraquin, 1998; Thompson, 1998; Girardi, 1999) suggests that environmental disclosure is increasingly affecting factors such as cost of capital, ease of access to finance and market valuation of the firm. For example, disclosures about the firm's regulatory compliance in the Director's Report could influence availability and cost of borrowing and insurance. However, there is little empirical evidence about the relative influence of these costs on capital investment decisions. Prakash and Kollman (2004) note that mandatory information disclosure increases the amount of environmental information available to shareholders, consumers and other stakeholders.

\subsubsection{Accounting disclosures}

According to Deegan and Rankin (1996), Australian companies believe there is a relationship between positive environmental disclosures and profitability.

(C) The Authors

Journal compilation (C) 2006 AFAANZ 
This suggests that there is potential power in mandatory disclosure requirements. Firms that must make 'bad news' environmental disclosures might feel pressured to improve their performance. Still, mandatory environmental disclosure requirements remain in the introductory stage with many inconsistencies. For example, environmental disclosures are required by extractive industry accounting standard, AASB 1022, particularly regarding provision for site restoration. Other industries also have significant need to consider site restoration, but there are no standards or regulations that require firms in other industries to make such disclosures. Also, although Auditing Guidance Statement AGS 1036 requires auditors to consider environmental matters in the financial statement audit, 'there is no governing accounting standard by which to audit' (ICAA, 1998).

\subsubsection{Corporations law requirements}

The Corporations Act 2001 s. 299 (1)(f) requires disclosure in the annual Directors' Report as follows:

If the entity's operations are subject to any particular or significant environmental regulation under a law of the Commonwealth, or of a State or Territory - give details of the entity's performance in relation to the environmental regulation.

The requirements are not related specifically to financial disclosures (e.g. contingent liabilities and capital commitments) but rather to performance in relation to environmental regulation. Frost and English's (2002) study found that s. 299(1)(f) has been successful in increasing the level of reporting of information, which is useful to environmentally concerned stakeholders. However, Burritt (2002) notes criticisms of s. 299(1)(f) and suggests that the Directors' Report is not an appropriate location for environmental reporting.

\subsubsection{National pollutant inventory}

The National Pollutant Inventory (hereafter referred to as the Inventory) is an Internet database implemented by Commonwealth, State and Territory Governments of Australia. ${ }^{2}$ It provides information to community, industry and government regarding selected chemicals being emitted to the environment. The Inventory is intended to make companies more accountable and to provide an incentive for cleaner production, as facilities (and members of the public) can compare their performance.

Several reports evaluating the Inventory are available on the Inventory site. These include an evaluation (ARTD, 2000) of the potential benefits of the

\footnotetext{
${ }^{2}$ The National Pollutant Inventory can be accessed at http://www.npi.gov.au/.

(C) The Authors

Journal compilation (C) 2006 AFAANZ
} 
Inventory. One probable benefit suggested by some industry groups (p. 67) was that publicly available information would be a powerful motivator to industry to demonstrate improved environmental performance to stakeholders.

Some indication of the likely influence of the Inventory can be gained from Cohen (1997), who reports on the US Toxic Release Inventory. The Toxic Release Inventory does not require firms to reduce their emissions but mandates that they publicly disclose the amount of toxic chemicals released. Around the time of the initial disclosure the highest polluters lost an average of 1.2 per cent of their market value. He notes that these firms reduced their Toxic Release Inventory emissions more than their industry peers. Howes (2001) suggests that the success of Australia's Inventory could depend on whether community groups use the information and act as 'watchdogs'.

\subsection{Regulatory costs}

Regulation of firm environmental performance is carried out mainly by the state EPAs. EPAs impose charges for pollution, such as licensing costs, emission and disposal charges, and fines and penalties. Regulatory costs might include ex-ante interventions, such as prohibition from operating for firms who fail to comply with regulations, and ex-post interventions through liability after a firm has already created a social cost by environmental damage (Boyd, 1997).

Regulatory costs include charges for pollutant emissions and clean-up costs. Pollutant emissions are taxed by EPAs through 'user-pays' charge systems, such as load-based licensing. Water authorities also allow disposal of some trade waste through the sewerage system, although the principle of 'user-pays' does not seem to be applied to trade waste schemes. Load-based licensing (LBL) is an emissions charge scheme that shifts the primary focus of the licensing system from controlling concentrations of pollutants in emissions, to controlling the total mass (or load) of pollutants discharged.

One of the objectives of LBL is to encourage the adoption of cleaner technologies (EPA (NSW), 1998). This implies the need for capital investment, yet little attention has been given by researchers or regulators to investigating emission taxes as motivators for increased investment in cleaner technology. Hamilton et al. (1997; Section 6.3) comment that 'the impact of existing systems of load-based licensing is difficult to assess at this stage, but they appear to be significant motivating factors in reducing pollution'. However, EPA (NSW) (1998) indicates that for load-based licensing the 'expected level of abatement (and therefore associated costs) are key unknowns and difficult to predict with any degree of confidence'. The EPA (NSW) study indicates that charges for pollutant emissions are quite low in New South Wales in comparison with international standards. A UK study of environmental regulation (Fineman, 2000 , p. 62) found regulatory officials to have a "technicist "shallow green" perspective' which leads to 'satisficing'. Given the similarity of cultures, it is likely that regulatory officials would operate in a similar manner in Australia.

(C) The Authors

Journal compilation (C) 2006 AFAANZ 
Evidence regarding site clean-up (Bates, 2000) suggests that the liability for clean-up of polluted sites, although less in Australia than in the USA, can be very costly. The published literature lists several costs arising from site pollution. These include impairment of the firm's assets and possible shutdown of facilities (CICA, 1993) as well as related costs such as adverse publicity, increase in insurance premiums and disruption to business (Brennan, 1995).

\subsection{Subsidization}

Environmental subsidies include direct payments and tax concessions for environmental protection or improvement. Environmental impact and protection expenditure is dealt with in Division 400, Part 3-45 (1997) of the Income Tax Assessment Act. Concessional tax treatment is provided by allowing immediate deductibility for expenditure incurred for the sole or dominant purpose of carrying on environmental protection activities (section 400-55). However, capital investment for the purpose of preventing or reducing pollution might not qualify for depreciation allowances if the investment is not income producing. Therefore, section 400-100 treats property used for environmental protection activities as if it were used for the purpose of producing assessable income (Woellner et al., 2001). Deutsch et al. (2001, p. 578) explain that this has the effect of bringing 'capital expenditure on buildings used for environmental protection purposes within the net of Division 43, provided that capital expenditure meets the other tests of the division'. However, the concession is very small (depreciation within the range of 2.5-4 per cent). Capital expenditure on environmental plant and equipment is deductible only at the same rate as for investments in plant and equipment used in income-producing operations. The Australia and New Zealand Environment and Conservation Council (ANZECC) (1998) criticizes of the lack of incentive in the deductions allowed by the Australian Tax Office. They add (p. 75) that it must be noted that these existing concessions have not been widely promoted and so their effectiveness has not been fully tested'.

Some limited use has been made of direct subsidization by state EPAs. This assistance is aimed mainly at small to medium-sized firms and makes some funding available through partnership programmes. Grants are provided by EPAs to assist with initiatives by firms such as redesigning processes to reduce waste and implementation of cleaner production technology. The only environmental subsidy available to all Australian firms is indirect subsidization provided by the Australian Tax Office, through depreciation allowances. ${ }^{3}$

Dodds (1999) questions the value of environmental tax concessions as the incentive provided is unlikely to be set at the optimal rate'. Indications of the

\footnotetext{
${ }^{3}$ Because depreciation allowances are the only subsidy available to all firms, the present study is limited to testing subsidy through tax concessions in the form of depreciation allowances.

(C) The Authors

Journal compilation (C) 2006 AFAANZ
} 
effectiveness of these tax concessions are derived mostly from economic projections, rather than from empirical research. Lockhart's (1997) US study suggests that investigation is needed to determine 'whether tax preferences can be effective in changing behaviour to actions aimed at environmental protection'.

The scarcity of literature on the effect of tax concessions and direct subsidies suggests the need for a better understanding of their influence. However, there is some evidence that subsidies to encourage environmental improvements are effective. ${ }^{4}$ Rae (1997) suggests that in situations where the desired behaviour is unlikely to occur without some financial incentive, subsidies might be appropriate.

\subsection{Stakeholder opinion}

Key (non-government) stakeholders include banks and other creditors, investors, insurance companies, employees, customers and green pressure groups. The opinion of various stakeholders is held to pressure firms to improve their environmental performance. Several studies suggest that stakeholders, such as investors and customers, have an influence on firms' environmental performance (see Mitchell et al., 1997; Nasi et al., 1997). Heinkel et al. (2001) conclude that exclusionary ethical investing leads to lower stock prices and, consequently, higher costs of capital for polluting firms. However, they suggest that although more than 20 per cent green investors are needed to induce polluting firms to reform, only approximately 10 per cent of investment is currently managed under social responsibility guidelines.

An Australian study by Girardi (1999) suggests increasing awareness of environmental issues by banks, insurers and credit rating agencies. This is consistent with studies from other developed countries (Schmidheiny and Zorraquin, 1998; Thompson, 1998; Gunningham et al., 1999; Randjelovic et al., 2003). Still, uncertainties remain about the nature of management response to environmental pressures from stakeholder groups and the degree of their influence on decision-making. Delmas and Toffel (2004) put forward a useful model to 'evaluate relative influences of external stakeholders exerting institutional pressures on firms'. However, this model as yet remains untested.

\subsection{Human information processing for the capital investment decision}

Some understanding of rational decision-making by individual capital investment managers can be gained from the human information processing and decision-making literature. Human information processing in the context of decision-making is described by Al-Khafaji et al. (1993, p. 44):

\footnotetext{
${ }^{4}$ For further information, see http://www.denr.sa.gov.au/epa/wastepaper.html.
} 
Conditions of uncertainty require decision makers to use their interpretive skills in their search for information. One reason for the use of such skills is that information may be cast in the form of signals or cues which could be singly or batch fed to a decision maker. In this case, one would expect such cues to concurrently contain information which could be redundant or overlapping with alternate cues. In the absence of a direct exposure to the occurrence of a given event (certainty), cues would help a decision maker to estimate the most likely (probabilistic) outcomes about the desired environment, i.e. to formulate judgements.

After estimating likely outcomes, the rational decision-maker can make choices, which are described by March (1994) as preference-based and pursuing a 'logic of consequence'. Therefore, the decision depends on expectations of 'future effects of current actions' and an evaluation of these future effects in terms of the personal preference of the decision-maker (and/or company policy). The choice depends on available alternatives, expectations of consequences, preferences, and the decision rule (how the choice is made among alternatives according to assigned value of the consequences) (March, 1994). Beach et al. (1992) note that before deliberations take place, the decision is 'framed' or put into a context, which classifies the decision according to the type of situation, issues, goals and plans, or importance to the decision-maker or organization.

Maines (1995, p. 77) notes that 'decision makers often believe that their decision processes involve complex information evaluation and integration strategies' where 'evaluation of one piece of information depends on the specific value of another piece of information, which suggests configural or interactive information processing'. In the accounting literature, auditors were found to use configural cue processing by Brown and Solomon (1991) and Hooper and Trotman (1996). If managers evaluate cues configurally they might, for example, evaluate the impact of pollution charges together with a depreciation allowance, to form a combined cue 'net pollution costs'. This is important to the present paper's research objectives because a finding of configural cue processing would be an indication that the ESCs have an influence not only as separate measures (main effects) but also in combination with one another (interactions). Such a finding might suggest the need to consider these combined effects when formulating ESCs.

Cue configurality has been linked to self-insight in decision-makers. The research indicates that decision-makers who process cues configurally might have higher levels of decision confidence, consistency and accuracy. Solomon and Shields (1995, p. 151) note that self-insight has 'typically been assessed as the correlation, over all cues, between a subject's cue usage and the importance rating subjectively attached to each cue (e.g. by allocating 100 points among the cues)'. Gibbins and Swieringa (1995) note that auditors have been found to have a high degree of self-insight, which they attribute (p. 245) to a 'professional environment in which one is expected to know how one's choices were made' and to 'significant task relevant experience and expertise'. These

(C) The Authors

Journal compilation (C) 2006 AFAANZ 
same factors can reasonably be expected to apply to capital investment managers.

\subsection{The capital investment decision}

Australian capital budgeting evaluation practices are consistent with those of other developed countries (Kester et al., 1999). Studies of capital investment decision-making (such as Butler et al., 1993) and of environmental capital investment decision-making (such as White et al., 1995) have found that a tiered structure for capital investment decision-making is common. After analysis and recommendation on project attractiveness by capital investment managers, the final decision for large projects is generally taken at the senior management level.

\section{Research questions and method}

The above literature posits that each of mandatory disclosure, subsidization, regulatory costs and stakeholder opinion impact upon the decision-maker's judgement as to the acceptability of a capital investment. However, the extant published literature has not yet set out the relative importance of each of these four ESCs in the decision. To remedy this deficiency, the following main research question (MRQ) is posed:

MRQ: What is the relative importance to individual capital investment managers of mandatory disclosure, regulatory costs, subsidization and stakeholder opinion in the assessment of capital investment?

Work on human information processing shows that the relative importance of factors can be a result of both their main effects and their interactive effects (Brown and Solomon, 1991; Hooper and Trotman, 1996). Hooper and Trotman conclude that configural cue processing and self-insight are desirable and reduce inconsistencies in decision-making. Finally, managerial self-insight has been seen as related to decision confidence and accuracy by Hooper and Trotman (1996). To better gauge the importance of these factors and to provide valuable insight into the possible benefits of managing ESCs with fuller knowledge of their joint effects, the following subsidiary research questions (SRQ) are posed:

SRQ1: Do capital investment managers process environmental cues configurally when assessing the acceptability of a capital investment proposal?

SRQ2: What is the degree of self-insight experienced by capital investment managers when making capital investment decisions?

Experimentation is well established in decision-making research (namely, Finucane et al., 2000; Forlani, 2002) and has been frequently used for the investigation of auditor decision-making (namely, Brown and Solomon, 1991;

(C) The Authors

Journal compilation (C) 2006 AFAANZ 
Ashton and Ashton, 1995; Hooper and Trotman, 1996; Trotman, 1996). Butler et al. (1993) and Kester et al. (1999) use an experimental method to research capital investment.

In this experiment the four ESCs (namely, mandatory disclosure, regulatory costs, depreciation allowances and stakeholder opinion) were varied to gauge their influence on the acceptability of the capital investment. Subsidization was termed 'depreciation allowances' for ease of understanding by the investment managers, as depreciation is the main method of environmental subsidization used in Australia. The experiment was analysed using analysis of variance (ANOVA) and power estimates were taken to disclose the experiment's ability to detect significant differences.

A fully crossed factorial experiment was chosen as the most appropriate method to address the research questions because factorial experiments allow determination of interactive effects of independent variables as well as main (independent) effects. Possible interaction effects are considered significant in this study as finding important interactive effects would indicate that the ESCs might be more effectively applied in certain combinations, rather than individually.

A repeated measures or 'within-subjects' design was used where all levels of treatment are applied to each subject. The elimination of random error as a result of individual differences and multiple treatments possible for each subject results in increased power of the experiment according to Mitchell and Jolley (1992). They note that 'in the simplest case your subjects serve double duty by being in both control and experimental conditions' (p. 300).

Mitchell and Jolley (1992) suggest that treatment carry-over effects are the major disadvantage associated with this design but these effects are minimized when the respondents are familiar and practiced with the task. Because the experiment imitates key elements of the decisions made on a regular basis by capital investment managers, the subjects are performing a task that is familiar to them.

\subsection{Variable definition and measurement}

A major consideration concerning variable definition and measurement was the selection of categorical levels. Many levels of ESCs are possible and testable. However, each increase in the number of levels has the major disadvantage of increasing the complexity of the experiment. To avoid this problem operationalization of the independent variables was restricted to two levels: 'better' and 'worse'. Better meant 'better than your last capital investment decision' and worse meant 'worse than your last capital investment decision'. Kida et al. (1990, p. 358) note that 'categorizing the data is not only required for ANOVA modelling, it is also a heuristic typically used in the decision process'. They point out that decision-makers, faced with large amounts of numerical data, translate it into qualitative terms to make the numbers meaningful. Therefore,

(C) The Authors

Journal compilation (C) 2006 AFAANZ 
'cues are often given different categorical descriptions such as above/below average, high/low, up/down, rising/falling, etc.' (Kida et al. 1990).

Three measures were used to answer the MRQ; namely,

1 Self-reported weightings: To measure their self-insight, respondents were asked to carry out a self-reported weighting of the variables. This involved dividing 100 points among the four ESCs to indicate the weight of each in their decision-making. This provides a subjective measure of the influence of the ESCs on capital investment.

2 Magnitude of effect measurements: This measure change in the mean investment judgement brought about by moving from a 'better' to a 'worse' level for the four ESCs. This measure was calculated separately for each of the four ESCs on each manager's assessment of the favourableness of the capital investment.

3 Effect size: Effect size was measured by summing each ESC's main effect and interactions found to be significant in the capital investment decision. Effect size was calculated using eta squared, which sets out the proportion of variance explained by each of the factors.

The influence of the ESCs on the dependent variable was measured in terms of perceived acceptability of the project. Perceived acceptability was measured using a 7-point scale anchored with $1=$ low acceptability and $7=$ high acceptability with a zero value indicating no change in project acceptability. Interestingly, no zero scores were recorded: a finding which indicates that each case of ESC combinations was perceived as changing project acceptability.

Before mailing, pilot tests were conducted with 7 capital investment managers, to remove ambiguities and ensure that the experiment was a valid replication of the decision managers make regarding environmental factors. The experiment was posted to 65 financial managers involved in capital investment decision-making and 41 useable responses were received (a response rate of 63 per cent).

\section{Results}

The findings of the study are presented for: (i) the relative weights of the ESCs; (ii) the use of configural cue processing in capital investment decisionmaking; and (iii) the degree of self-insight experienced by the capital investment managers.

\subsection{ESC weightings}

To address the MRQ regarding the relative influence of each ESC, relative ESC weights were derived from self-reported weightings, magnitude of effect measurements, and effect size measurements. These weights are shown in Table 1. 
Table 1

ESC weightings

\begin{tabular}{|c|c|c|c|c|}
\hline & $\begin{array}{l}\text { Mandatory } \\
\text { disclosure }\end{array}$ & $\begin{array}{l}\text { Regulatory } \\
\text { costs }\end{array}$ & Subsidization & $\begin{array}{l}\text { Stakeholder } \\
\text { opinion }\end{array}$ \\
\hline Self-reported weights (\%) & 11.98 & 19.32 & 28.34 & 40.60 \\
\hline Standard deviation & 8.82 & 11.40 & 17.51 & 19.61 \\
\hline Range $(\mathrm{L}-\mathrm{H})(n=41)$ & $0-35$ & $0-50$ & $5-90$ & $0-80$ \\
\hline Rank order & 4 & 3 & 2 & 1 \\
\hline \multicolumn{5}{|l|}{ Magnitude of effect ${ }^{a}$} \\
\hline \multicolumn{5}{|l|}{ Rating } \\
\hline Better & 3.8292 & 4.0518 & 4.1219 & 4.3780 \\
\hline Worse & 3.0762 & 2.8537 & 2.7835 & 2.5274 \\
\hline Difference & 0.753 & 1.1987 & 1.3384 & 1.8506 \\
\hline$\%$ of summed differences $(n=41)$ & 15 & 23 & 26 & 36 \\
\hline Rank order & 4 & 3 & 2 & 1 \\
\hline \multicolumn{5}{|l|}{ Effect size } \\
\hline Main effects percentage (total = 92) & 9.33 & 21.4 & 25.80 & 42.40 \\
\hline Interactions $(\%)($ total $=8)$ & 0.06 & 0.06 & 0.06 & 0.06 \\
\hline Combined effect $(\%)($ total $100, n=41)$ & 9.39 & 21.46 & 25.86 & 42.46 \\
\hline Rank order & 4 & 3 & 2 & 1 \\
\hline
\end{tabular}

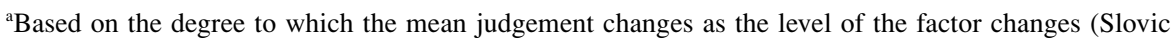
et al., 1972).

\subsubsection{Self-reported weightings}

The self-reported weightings are a subjective measure of managers' perceptions of the weight of each ESC. Stakeholder opinion was weighted more heavily than any of the other ESCs. The individual mean ratings derived from this measure indicate that stakeholder opinion, with a weight of 40.6 per cent, has a much greater influence than subsidization (28.34 per cent) and regulatory costs (19.32 per cent). Mandatory disclosure had a relatively very low weight of only 11.98 per cent.

The relatively high standard deviations for stakeholder opinion and subsidization (19.61 and 17.51, respectively) suggest more variability among the managers on the weighting of these two variables. In comparison, the standard deviations of 11.4 for regulatory costs and 8.82 for mandatory disclosure indicate increased commonality among the managers about the weights of these two ESCs.

\subsubsection{Magnitude of effect measurements}

The magnitude of effect measurements also suggest that stakeholder opinion is the most influential ESC. By this measure stakeholder opinion scored slightly lower (36 per cent) than by the self-reported weightings (subsidization similarly slightly lower at 26 per cent). However, this measure still supports the finding 
that these two variables had the highest weights. Regulatory costs (23 per cent) and mandatory disclosure (15 per cent) were weighted slightly higher by this measure than the self-reported weightings. These weightings also support the findings of the self-reported weightings about the ranking order of the variables, with regulatory costs third and mandatory disclosure again the lowest weighted variable.

\subsubsection{Effect size measurements}

The effect size measurements of each ESC's main effect and interactions support the findings of the previous two measures, indicating that stakeholder opinion has the highest weighting (42.46 per cent), followed by subsidization ( 25.38 per cent) and regulatory costs (21.46 per cent), with mandatory disclosure lowest ( 9.39 per cent). The combined effect sizes were obtained by allocating the significant interactions to the main effects for each ESC. ${ }^{5}$ However, the effect sizes for both interactions were similarly very small relative to the main effects and contributed little weight to the combined effect sizes. The findings of the three measures used in the experiment are in agreement regarding the rank order of influence and show fairly similar findings on the weightings of the ESCs. This correspondence between the three measures provides reassurance as to the validity of the findings of the experimental study.

\subsection{Configural cue processing}

To address SRQ1 regarding ESC cue configurality, evidence regarding whether the investment managers use cues individually or configurally is presented in Table 2. Interactions found to be significant are an indication of configural cue processing. Evidence consists of the effect size for each social control main effect and interaction found to be significant $(p<0.05)$ as well as its $F$-value, significance and the power of the test of significance.

Statistically significant interactions were detected between: (i) regulatory costs and subsidization; and (ii) stakeholder opinion and disclosure. In the case of the first interaction it appears that respondents could be offsetting subsidization against the costs of regulation, forming a combined cue, which might be termed 'net regulatory costs'. In the second case respondents could be combining mandatory disclosure with stakeholder opinion, to form a combined cue, which might be termed 'net effect on stakeholder opinion'. However, both pairs of interactions account for only a very small part of the decision compared to the main effects.

\footnotetext{
${ }^{5}$ Half of each eta squared value for the interactions was allocated to the two relevant variables. For example, half of the eta squared value for the regulation-subsidization interaction was added to the regulation main effect and half to the subsidization main effect.
}

(C) The Authors

Journal compilation (C) 2006 AFAANZ 
Table 2

Social controls main effects and interactions

\begin{tabular}{llrlr}
\hline Factor & Effect size & $F$-value & Significance & Power \\
\hline Main effects & & & & \\
$\quad$ Subsidization (S) & 0.177 & 137.227 & $0.000^{* *}$ & $0.000^{* *}$ \\
$\quad$ Disclosure (D) & 0.064 & 43.441 & $0.000^{* *}$ & 1.00 \\
$\quad$ Regulatory costs (R) & 0.147 & 109.975 & $0.000^{* *}$ & 1.00 \\
$\quad$ Stakeholder & 0.291 & 262.535 & & 1.00 \\
$\quad$ Opinion (SO) & & & & $0.035^{*}$ \\
Interactions & 0.007 & 4.444 & $0.040^{*}$ & 0.558 \\
$\quad$ S $\times$ R & 0.007 & 4.222 & & 0.537 \\
$\quad$ MD $\times$ SO & 0.014 & & & \\
$\quad$ Total interactions & 0.693 & & & \\
Sum of effect sizes & & & & \\
\hline
\end{tabular}

**Significant at $0.01 ; *$ significant at 0.05 .

\subsection{Self-insight}

SQR2 asks about the degree of self-insight experienced by capital investment managers. As shown in Table 1, the mean self-insight scores for the ESCs were fairly similar to the scores for the effect size, suggesting a high degree of selfinsight for most managers. The managers responding to the experimental study also rated their level of confidence highly in their decisions. The high level of confidence displayed by the managers is also consistent with the view of Hooper and Trotman (1996) that self-insight is related to decision confidence.

\section{Conclusions}

ESC weights have important implications for both environmental policy setting and capital investment decision-making. Unless ESCs have substantial weight in the capital investment decision, they are unlikely to effect the changes in behaviour that society is seeking. Stakeholder opinion is a very important social control, with approximately 40 per cent of the combined weight of the ESCs. This suggests that managers are much more responsive to stakeholder opinion than they are to regulatory costs, subsidy or mandatory disclosure. This is important because it supports the current trend towards the use of economic instruments as an alternative or adjunct to 'command and control' regulation. It further adds support to the views of Schmidheiny and Zorraquin (1998) and Gunningham et al. (1999) on the effectiveness of market forces as a means of influencing firm environmental performance and their further use as ESCs. As economic instruments rely on harnessing market forces, they are more likely to be successful if managers are responsive to stakeholder opinion. 
Subsidization, the 'carrot' among social controls, was found to be an influential factor, with a weighting of 27 per cent. This was second only to stakeholder opinion. The relatively high level responsiveness of managers to change in the level of subsidy suggests that managers would be very responsive to increased subsidization. This finding adds support to the suggestion in the published literature (Lockhart, 1997; EPA (South Australia), 2001) that subsidies can be very effective as an incentive for environmental improvement. The experiment adds support to the conclusion that there is room for increased use of subsidization. Some (or all) of the cost to government might be offset by increased tax receipts from higher profits made by firms, savings in the cost of 'policing' of small firms, and reduction in environmental damage.

Regulatory costs was weighted only third in influence, with a weight of 21 per cent (range 19-23 per cent). The findings of Sharma et al. (1999) suggest a possible reason for this finding. They found that many managers have instructions to 'invest only enough to get a clean chit from the regulators'. Overall, the weight-accorded regulatory costs are somewhat less than desirable from an environmental point of view.

Mandatory disclosure is by all measures clearly the least influential variable. The experimental weightings average only 12 per cent (range 9-15 per cent) of the combined ESC weights. It is apparent that for many managers the high influence of stakeholder opinion does not translate into concerns about mandatory environmental disclosure. Increased education of managers about disclosure requirements and widening the application of disclosure requirements might increase their effectiveness.

Capital investment managers were found to use configural cue processing in making their capital investment decisions, but only to a limited extent. Statistically significant interactions were found between subsidization and regulatory costs and also between mandatory disclosure and stakeholder opinion. However, despite their statistical significance, the effect sizes for the two pairs of interactions are quite small relative to the main effects. This suggests that ESC policy coordination is not a paramount concern. Overall, the managers also displayed a high degree of self-insight into their decisions as well as decision confidence. This finding suggests that managers are quite aware of the impact of the individual ESCs on their capital investment decisions. Accordingly, those agencies charged with ESC policy setting would be well advised to consult closely with capital investment managers when considering ESC initiatives.

This research naturally opens new areas for inquiry. First, it is clear that the ESCs considered are uniquely Australian. Any generalization outside of Australia is problematic. New research ought to extend this paper's inquiries to other places with differing ESC mixes. Case study based rich description could be used to move beyond the confines of the experimental levels and provide full description of how each of ESCs could be made more valuable to capital investment decision-makers. Moreover, a fuller description of just how the 
acceptability of capital investments is reduced or improved by changing ESCs conditions is required.

\section{References}

Al-Khafaji, A., I. M. Aly, K. F. Gheyara, and S. Metawae, 1993, Behavioral judgment and cue utilization: the case of corporate takeovers, Managerial Finance 19, 43-54.

ARTD Management and Research Consultants, 2000, Evaluation of the National Pollutant Inventory Program, Report to Chemicals and the Environment Branch, Environment Australia, EPA (NSW) [online]. Available: http://www.npi.gov.au/about/review/pubs/ evaluation.pdf

Ashton, R. H., and A. H. Ashton, (eds.), 1995, Judgment and Decision-Making Research in Accounting and Auditing (Cambridge University Press, Cambridge).

ANZECC (Australia and New Zealand Environment and Conservation Council), 1998, Towards Sustainability: Achieving Cleaner Production in Australia (Australian Department of Environment and Heritage, Canberra, ACT).

Bansal, S., and S. Gangopadhyay, 2003, Tax/subsidy policies in the presence of environmentally aware consumers, Journal of Environmental Economics and Management 45, 333.

Bates, G. M., 2000, Environmental Law in Australia (Butterworths, Sydney, NSW).

Beach, L. R., T. R. Mitchell, T. F. Paluchowski and E. H. Van Zee, 1992, Image theory, decision framing and decision deliberation, in: F. Heller, ed., Decision-Making and Leadership (Cambridge University Press, Cambridge, MA) 173-188.

Bennear, L. S., and C. Coglianese, 2005, Measuring progress: program evaluation of environmental policies, Environment 47, 2.

Boyd, J., 1997, Green money in the bank: firm responses to environmental financial responsibility rules, Managerial and Decision Economics 18, 491-506.

Boyd, J., 1998, Searching for Profit in Pollution Prevention, Case Studies in the Corporate Evaluation of Environmental Opportunities, EPA 742-R-98-005 (US Environmental Protection Agency Office of Pollution Prevention and Toxics).

Brennan, M., 1995, Environmental law, Corporate Management, April, 120-126.

Brown, E. B., and I. Solomon, 1991, Configural information processing in auditing: the role of domain specific knowledge, Accounting Review 66, 100-119.

Burritt, R. L., 2002, Environmental reporting in Australia: current practices and issues for the future, Business Strategy and the Environment 11, 391-406.

Butler, R., L. Davies, R. Pike, and J. Sharp, 1993, Strategic Investment Decisions: Theory, Practice and Process (Routledge, London).

CICA (Canadian Institute of Chartered Accountants), 1993, Environmental Costs and Liabilities: Accounting and Financial Reporting Issues (CICA, Toronto, ON).

Cohen, M. A., 1997, Firm response to environmental regulation and environmental pressures, Managerial and Decision Economics 18, 417-420.

Deegan, C., and M. Rankin, 1996, Do Australian companies report environmental news objectively? Accounting, Auditing and Accountability Journal 9, 50-67.

Delmas, M., and M. W. Toffel, 2004, Stakeholders and environmental management practices: an institutional framework, Business Strategy and the Environment 13, 209-222.

Deutsch, R. L., I. G. Fullerton, M. M. Gibson, P. J. Hanley, W. S. Plummer, and T. J. Snape, 2001, Australian Tax Handbook (Australian Tax Practice, Pyrmont, NSW).

Dodds, S. H., 1999, Practical Issues in the Design of Environmental Taxes in Australia, paper presented at the Australian New Zealand Ecological Economics Society National Conference, Brisbane 5-7 July.

EPA (Environment Protection Authority) (NSW), 1994, Pollution Charge Systems: An Information Paper (EPA 94/63, Chatswood, NSW).

(C) The Authors

Journal compilation (C) 2006 AFAANZ 
EPA (Environment Protection Authority) (NSW), 1998, Regulatory Impact Statement: Proposed Pollution Control Regulation (EPA, Chatswood, NSW).

EPA (Environment Protection Authority) (South Australia), 2001, Small Business Pollution Prevention Project, EPA (South Australia) [online; cited 10 July 2001]. Available: http:// www.epa.sa.gov.au/casestudies.html

Fineman, S., 2000, Enforcing the environment: regulatory realities, Business Strategy and the Environment 11, 391-406.

Finucane, M. L., A. Alhakami, P. Slovic, and S. M. Johnson, 2000, The affect heuristic in judgements of risks and benefits, Journal of Behavioral Decision Making 13, 1-17.

Forlani, D., 2002, Risk and rationality: the influence of decision domain and perceived outcome on managers' high risk decisions, Journal of Behavioral Decision Making 15, 125 140.

Frost, G., and L. English, 2002, The introduction of mandatory environmental reporting in Australia: an analysis of the ex post reaction by industry and government, paper presented at the Critical Perspectives on Accounting Conference, New York, May.

Gibbins, M., and R. J. Swieringa, 1995, Twenty years of judgment research in accounting and auditing, in: R. H. Ashton and A. H. Ashton, eds, Judgment and Decision-Making Research in Accounting and Auditing (Cambridge University Press, Cambridge) 231-249.

Girardi, G., 1999, Accounting for Waste as a Business Management Tool: Best Practice Guideline (Management Accounting Centre of Excellence, Australian Society of Certified Practising Accountants, Melbourne, Vic.).

Gunningham, N., P. Grabowsky, and D. Sinclair, 1998, Smart Regulation: Designing Environmental Policy (Oxford University Press, New York, NY).

Gunningham, N., M. Phillipson, and P. Grabosky, 1999, Harnessing third parties as environmental regulators: achieving environmental outcomes by alternative means, Business Strategy and the Environment 8, 211-224.

Gunningham, N., R. Kagan, and D. Thornton, 2003, Shades of Green: Business, Regulation and Environment (Stanford University Press, Palo Alto, CA).

Hamilton, C., T. Hundloe, and J. Quiggin, 1997, Ecological tax reform in Australia, niscussion paper No.10 (The Australia Institute, Canberra, ACT).

Heinkel, R., A. Kraus, and J. Zechner, 2001, The effect of green investment on corporate behavior, Journal of Financial and Quantitative Analysis 36, 431-446.

Hooper, C., and K. Trotman, 1996, Configural information processing in auditing: further evidence, Accounting and Business Research 26, 125-136.

Howes, M., 2001, What's your poison? The Australian National Pollutant Inventory versus the US Toxic Release Inventory, Australian Journal of Political Science 36, 529-552.

ICAA (Institute of Chartered Accountants in Australia), Environmental Accounting Task Force, 1998, The impact of environmental matters on the accountancy profession, discussion paper (ICAA, Sydney, NSW).

Kester, G. W., R. P. Chang, E. S. Echanis, S. Haikal, M. Isa, M. T. Skully, K. Tsui, and C. Wang, 1999, Capital budgeting practices in the Asia-Pacific Region: Australia, Hong Kong, Indonesia, Malaysia, Philippines, and Singapore, Financial Practice and Education Spring/ Summer, 25-33.

Kida, T., J. Cohen, and L. Paquette, 1990, The effect of cue categorization and modeling technique on the assessment of cue importance, Decision Science 21, 357-372.

Lockhart, J., 1997, Environmental tax policy in the United States: alternatives to the polluter pays principle, Asia-Pacific Journal of Accounting December, 219-239.

Maines, L. A., 1995, Judgment and decision-making research in financial accounting: a review and analysis, in: R. H. Ashton and A. H. Ashton, eds, Judgment and DecisionMaking Research in Accounting and Auditing (Cambridge University Press, Cambridge) 76-101.

March, J. G., 1994, A Primer on Decision Making: How Decisions Happen (The Free Press, Macmillan, New York, NY).

(C) The Authors

Journal compilation (C) 2006 AFAANZ 
Mitchell, R. K., B. R. Agle, and D. J. Wood, 1997, Toward a theory of stakeholder identification and salience: defining the principle of who and what really counts, Academy of Management Review 22, 853-886.

Mitchell, M., and J. Jolley, 1992, Research Design Explained (Harcourt, Brace, Jovanovitch, College Publishers, Fort Worth, TX).

Moraga-Gonzalez, J. L., and N. Padron-Fumero, 2002, Environmental policy in a green market, Environmental and Resource Economics 22, 419-447.

Nash, I., and A. Awty, 2001, Just clowning around? Australian CPA March, 26-32.

Nasi, J., S. Nasi, N. Phillips, and S. Zyglidopoulos, 1997, The evolution of corporate social responsiveness, Business Society 36, 296-321.

Prakash, A., and K. Kollman, 2004, Policy modes, firms and the natural environment, Business Strategy and the Environment 13, 107-128.

Rae, J., 1997 Economic instruments for environmental protection, Environmental Economics Round Table (Environment Australia, Canberra, ACT).

Randjelovic, J., A. R. O'Rourke, and R. Orsato, 2003, The emergence of green venture capital, Business Strategy and the Environment 12, 240-253.

Schmidheiny, S., and F. J. Zorraquin, 1998, Financing Change: The Financial Community, Eco-Efficiency and Sustainable Development (MIT Press, Cambridge, MA).

Sharma, S., A. L. Pablo, and H. Vredenberg, 1999, Corporate environmental responsiveness strategies, Journal of Applied Behavioral Science 35, 87-108.

Skidmore, D., 1997, Encouraging sustainable business practice through managing policies and instruments dynamically, Business Strategy and the Environment 6, 163-167.

Slovic, P., D. Fleissner, and W. Bauman, 1972, Analysing the use of information in investment decision making: a methodological proposal, Journal of Business 45, 283-301.

Solomon, I., and M. D. Shields, 1995, Judgment and decision-making research in auditing, in: R. H. Ashton and A. H. Ashton, eds, Judgment and Decision-Making Research in Accounting and Auditing (Cambridge University Press, Cambridge) 138-175.

Thompson, P., 1998, Bank lending and the environment: policies and opportunities, International Journal of Bank Marketing 16, 248.

Trotman, K. T., 1996, Research Methods for Judgment and Decision Making Studies in Auditing, Coopers and Lybrand Accounting Research Methodology Monograph, no. 3 (Coopers and Lybrand and Accounting Association of Australia and New Zealand, Melbourne, Vic.).

Verbeke, A., and C. Coeke, 1997, Environmental taxation: a green stick or a green carrot for corporate social performance? Managerial and Decision Economics 18, 507-516.

White, A. L., D. E. Savage, J. Brody, D. Cavander, and L. Lach, 1995, Environmental Cost Accounting for Capital Budgeting: a Benchmark Survey of Management Accountants (The Tellus Institute for the Office of Pollution Prevention, Boston, MA).

Woellner, R. H., S. Barkoczy, S. Murphy, and C. Evans, 2001, Australian Taxation Law 2001, 11th edn (CCH Australia, North Ryde, NSW). 